\title{
Assessment of Lifetime Occupational Exposure in an Epidemiologic Study of COPD
}

\author{
Monica Graziani ${ }^{1}$, Brent Doney ${ }^{*}, 1$, Eva Hnizdo ${ }^{1}$, Jacqueline Villnave ${ }^{2}$, Victor Breen ${ }^{2}$, \\ Sheila Weinmann ${ }^{2}$, William M. Vollmer ${ }^{2}$, Mary Ann McBurnie ${ }^{2}$, A. Sonia Buist ${ }^{3}$ \\ and Michael Heumann ${ }^{4}$
}

${ }^{I}$ National Institute for Occupational Safety and Health, Morgantown, WV, USA

${ }^{2}$ Kaiser Permanente Center for Health Research, Portland, OR, USA

${ }^{3}$ Oregon Health \& Science University, Portland, OR, USA

${ }^{4}$ Oregon Department of Human Services, Portland, OR, USA

\begin{abstract}
Ascertainment of lifetime occupational exposures in an epidemiological study of chronic obstructive pulmonary disease (COPD) is important in order to investigate its effect on the disease and develop prevention strategies. The aim of our paper is to describe and evaluate a methodology used to assign lifetime occupational exposure to participants in a case-control study of COPD where lifetime occupational history was ascertained through telephone questionnaire interviews.

The methodology involved assigning to each individual a qualitative index of potential exposure to eight occupational hazards, summarized individually overall the job categories reported by the individual, and an overall qualitative index of lifetime exposure to all eight hazards. The eight occupational hazards scored were mineral dusts, metal dusts/fumes, organic dusts, irritant gases/vapors, sensitizers, organic solvents, diesel exhaust, and environmental tobacco smoke (ETS). Two industrial hygienists independently assigned the above indices based on: their expert opinion, a priori knowledge based on literature review, and study participants' responses to interviewer questions regarding types and duration of exposure. To evaluate agreement of the assigned scores, we used the Kappa statistic to test the agreement between the two scorers on each of the indices. The Kappa statistic generally indicated good agreement between the industrial hygienists' scores but varied by exposure from 0.42 to 0.86 . Although the exposure scoring is somewhat subjective, it is based on experience of experts and review of the literature. This method, with subject interviews providing qualitative lifetime exposure data when air monitoring has not been conducted, is useful for reconstructing lifetime exposures.
\end{abstract}

Keywords: Chronic obstructive pulmonary disease, occupational exposure, diesel exhaust, epidemiology.

\section{INTRODUCTION}

Chronic obstructive pulmonary disease (COPD) is the fourth leading cause of death among persons older than 45 years of age in the United States [1]. Although cigarette smoking is the most important risk factor worldwide for COPD, occupational exposures to mineral and organic dusts, irritant gases and fumes, and to other industrially produced or used agents have been established as risk factors for COPD [2-14]. Industry- and population-based epidemiological studies have reported increased risk of COPD due to occupational exposures or due to employment in certain industries or job categories. Occupational groups reported to have increased risk of COPD include coal miners, hard rock miners, tunnel workers, concretemanufacturing workers, construction workers, agricultural workers, and some manufacturing workers [2, 3, 6-9]. COPD etiology is multi-factorial in nature and is strongly associated with non-occupational factors such as tobacco smoking. In

*Address correspondence to this author at the National Institute for Occupational Safety and Health, 1095 Willowdale Road, Morgantown, WV 26554, USA; Tel: +1-304-285-6357; E-mail:bdoney@cdc.gov addition, the combined effect of workplace respiratory hazards and tobacco smoking results in a higher risk of developing obstructive airways disease than would be expected from the additive effect of the individual exposures [13]. Because of the complex etiology, establishing workrelated risk factors for COPD requires an epidemiological investigation involving reliable measures of occupational exposure and smoking. When evaluating the risk of COPD associated with occupational exposure in population-based studies, evaluation of occupational exposure is often done through the use of a Job Exposure Matrix (JEM) [7, 15, 16]. The JEM is utilized to assign qualitative indices to specific job categories to indicate the potential for workers' exposure to vapors, dust, gases, and fumes (VDGF). In this study, however, we obtained individuals' lifetime occupational histories together with a relatively detailed interview using a questionnaire on exposures to specific agents for each job, therefore we did not use the standard JEM methodology.

This paper describes and evaluates the methodology used to assign occupational exposure using relatively detailed lifetime occupational history in a United States populationbased case-control study of work-related COPD [11]. The lifetime occupational history was ascertained through 
telephone questionnaire interviews and this information together with expert assessment based on literature review was used to assign an index of exposure for a job category for each of several potential occupational hazard categories. The novel aspect of the study was that we evaluated the workers' potential for exposure to the following eight occupational hazards for COPD: mineral dusts, metal dusts/fumes, organic dusts, irritant gases/vapors, sensitizers, organic solvents, diesel exhaust, and environmental tobacco smoke (ETS).

\section{METHODS}

The exposure assessment was done blindly for a set of 388 cases with COPD and 356 age-, sex-, and smokingfrequency matched controls selected from the membership of a health maintenance organization (Kaiser Permanente Northwest - KPNW). The participants were mainly employed by the industries in Northwest Oregon and Southwest Washington that have insurance with KPNW or were retired. The cases were 45 years and older; among cases the mean age was 67 and $44 \%$ were male whereas the mean age of controls was 66 and $41 \%$ were male. The study protocol and recruitment procedures for this study were approved by the participating institutions' human subjects committees. Details of the case-control study design are provided elsewhere [11].

\section{Occupational Data Collection}

Occupational history data were obtained through telephone interviews, by interviewers blinded to the casecontrol status. Using standard questionnaires the interviews collected information on demographics, past medical history, smoking history and detailed work history. The questions ascertained work descriptions for each job held for six months or longer, including when the job began and ended, actual number of years worked, and use of respiratory protection. Participants were also asked for each job if they were routinely exposed to dust, fumes, smoke, diesel exhaust, gases, or vapors while they were working on that job. Routinely exposed meant once per week or more. Participants were subsequently asked if their job routinely involved the use of chemicals, meaning things like solvents, cleaning agents, adhesives, paints and other coatings, pesticides, compressed gases, and cutting oils, as well as other chemicals. For a positive response, workers were then asked to describe more specifically what kind of exposures it was (e.g., silica dust under the dust category).

The questionnaires were used to collect information on a maximum of eight (longest held) jobs, which was sufficient for most participants, where more jobs were involved, similar jobs were combined. Similar jobs, i.e. jobs in the same industry and occupational categories, were combined together, following our protocol, in jobs where exposure to the agents of concern was unlikely, e.g., office workers. For the purposes of this study, "work" was defined as regular employment over six months in which the person received a paycheck and worked at least 4 hours/week; work was not a hobby, volunteer work, or occasional performance of a task. Participants were asked to characterize exposure to ETS and hobbies they were involved in away from the workplace. Participants were also asked how many years of their life had they lived with someone, other than themselves, who smoked inside the home. All responses were computerized and the duration of the interviews was approximately 30 minutes.

The professional research interviewers were specially trained on this project to conduct the interviews, and were continually evaluated and observed during the interviews to reduce recall and interviewer bias regarding the occupational histories. The initial training included review of the questionnaire, script, and procedures. The interviewers listened to taped interviews from a pilot study, and subsequently their interviews were taped and reviewed by senior staff and the industrial hygienist. Quality control by the industrial hygienist was conducted on the first few calls of each interviewer and was ongoing as needed. A feedback form was shared with the caller and their supervisor.

\section{Assessment of Occupational Exposure for Each Job Held}

The coding of occupational exposures for the eight types occupational hazards for COPD was done following a coding protocol developed at the onset of the survey. In preliminary research, the project industrial hygienists conducted a literature review to compile an occupational exposure reference list of industries and jobs in the United States based on the North American Industrial Classification System (NAICS) listing of industries, the 2000 Bureau of Census (BOC) list of jobs, and OSHA regulated exposure hazards $[17,18]$. In the exposure assessment, emphasis was placed on an occupation reference list (a working document) created by one of the industrial hygienist that utilized mainly the Encyclopedia [18] as referenced. The occupational exposure reference list included potential exposures such as: irritants and sensitizers, dust (metal, mineral and/or organic), organic solvents, diesel exhaust, and environmental tobacco smoke. The list was used by all the industrial hygienists as a framework for decisions on how to assign exposure scores to the eight potential occupational hazards. All the industrial hygienists were experienced at assessing occupational exposures and there was a continual quality control of the exposure scoring throughout the study using statistical evaluation.

Exposure scoring was done independently by two industrial hygienists (one from NIOSH and a Certified Industrial Hygienist from Kaiser Permanente Center for Health Research (KPCHR)) who were blinded to individual's disease- or smoking-status or other questionnaire responses (e.g., smoking, symptoms). For each job held, one industrial hygienist assigned a job and industry category based on 2000 Bureau of Census industry and occupation. This information was collected in order to describe the employment pattern of the study group so that this could be matched with the reference list.

A score for each of the eight potential occupational hazards was then assigned to each person for each job held based on the occupational exposure reference list and responses to the questionnaires regarding occupational exposure. All the eight exposure scores, with the exception of ETS, were assigned on a 3 -point scale of 0,1 , or 2 based on the likelihood of certain degree of exposure, where $0=$ no or minimal exposure, $1=$ moderate exposure, and $2=$ high exposure. ETS was scored as 0 or 1 where $0=$ no or minimal exposure and $1=$ moderate or high exposure. Score values were determined by industrial hygienists 
based on respondent answers to the questions that characterized each specific job with respect to exposure occurrences to various potentially hazardous agents and the type and toxicity of the agents.

\section{Assessment of Overall Exposure Scores}

The overall scores assigned to each person took into account the likelihood, intensity, and reported duration of exposure to the 8 potential occupational respiratory hazards for all the jobs held. The industrial hygienists relied upon professional knowledge and judgment as well as questionnaire responses on exposure characterization to assign an overall 3-point scale score of 0,1 , or 2 where $0=$ no or minimal exposure, $1=$ moderate exposure, and $2=$ high exposure to each person. See Appendix for an example of exposure scoring and the questionnaire.

\section{Environmental Tobacco Smoke (ETS)}

If the participant worked in an establishment where ETS exposure was potentially greater (waiter/waitress or bartender) than in other types of jobs where ETS exposure was potentially less, the overall job score was rated higher (score of 1 assigned regardless of exposure to other occupational hazards). Smoking status was not part of the ETS analysis. Industrial hygienists were blinded to the individual's smoking status and smoking status was handled separately.

\section{Quality Control of Exposure Assessment and Amendments to Study Protocol}

For reliability purposes, throughout the scoring process, exposures of about $10 \%$ of the case-control study subjects were independently scored by a Certified Industrial Hygienist (from NIOSH). For some exposure categories where scoring differences occurred, the protocol was amended to provide more guidelines on coding of some of the exposure categories to improve consistency of scoring.
Fig. (1) shows the agreement between NIOSH and KPNW coders on scores for the eight specific exposure categories for a person in a job. At the extremes, the measure of agreement, the Kappa coefficient, at or below 0.20 indicates slight agreement and above 0.81 indicates almost perfect agreement [19].

\section{Combining Exposure Scores in the Case-Control Data Analysis}

For the case-control data analysis [11], we used two algorithms to resolve differences between all exposure scoring by the KPNW and NIOSH industrial hygienists. The "conservative" algorithm used the lower of the two hygienists' exposure ratings unless one hygienist coded 0 and the other coded 2, in which case a score of 1 was used. The "liberal" algorithm used the greater of the two ratings, even in cases where one coded 0 and the other coded 2. For analyses, these combined exposure measures were further collapsed into "ever-exposure" (a combined measure of 1 or 2) versus "no exposure" (score of 0). Scores based on the "conservative" algorithm with the collapsed ever (1 or 2 ) versus never $(0)$ exposure categories constituted the primary exposure variables for the case-control analysis, while scores based on the "liberal" algorithm and those that used the trilevel $(0 / 1 / 2)$ ratings were used for sensitivity analyses.

\section{RESULTS}

Table 1 shows a list of exposures that were considered as potential respiratory hazard classifications for COPD and examples of each; diesel fumes and ETS are not included in the table. Table $\mathbf{2}$ characterizes the occupational exposure profile of the case-control study participants in terms of the type of occupational exposure category and the frequency with which the category was assigned in the case-control study [11], as described in Table $\mathbf{1}$ (and diesel fumes and ETS). The first three columns show the 27 main occupational categories coded across all study subjects and their frequencies. The top ten most frequent occupational

Table 1. Examples of Potential Respiratory Hazards ${ }^{\dagger}$ Grouped into Six Categories for Evaluation for Association with COPD

\begin{tabular}{|c|c|c|c|c|c|}
\hline $\begin{array}{l}\text { Mineral } \\
\text { Dusts }\end{array}$ & Metal Dusts and Fumes & $\begin{array}{c}\text { Organic } \\
\text { Dusts }\end{array}$ & Irritant Gas/Vapor & Sensitizers & Organic Solvents \\
\hline $\begin{array}{l}\text { Asbestos } \\
\text { Fiberglass } \\
\text { Silica } \\
\text { Coal } \\
\text { Graphite } \\
\text { Gypsum } \\
\text { Earth } \\
\text { Potash } \\
\text { Borate } \\
\text { Limestone }\end{array}$ & $\begin{array}{l}\text { Welding operations including soldering and grinding } \\
\text { Foundry operations } \\
\text { Copper } \\
\text { Beryllium }\end{array}$ & $\begin{array}{l}\text { Crops } \\
\text { Cotton } \\
\text { Wood } \\
\text { Lint } \\
\text { Flour }\end{array}$ & $\begin{array}{l}\text { Ammonia } \\
\text { Nitrogen oxides } \\
\text { Phosgene } \\
\text { Hydrogen sulfide } \\
\text { Chlorine } \\
\text { Fluorine } \\
\text { Benzene } \\
\text { Butadiene } \\
\text { Ketones } \\
\text { Polyvinylchloride } \\
\text { Phosphine } \\
\text { Acrylonitrile } \\
\text { Tetrachloroethylene } \\
\text { Carbon tetrachloride } \\
\text { Trichloroethylene } \\
\text { Metal mercury vapors }\end{array}$ & $\begin{array}{l}\text { Exotic woods } \\
\text { Glues } \\
\text { Insecticides } \\
\text { Formaldehyde } \\
\text { Insects } \\
\text { Vegetables } \\
\text { Animal dander } \\
\text { Plastics } \\
\text { Isocyanates } \\
\text { Metals (alkaline) } \\
\text { Welding operations } \\
\text { Cobalt } \\
\text { Chromium } \\
\text { Lead } \\
\text { Nickel }\end{array}$ & $\begin{array}{l}\text { Alcohols } \\
\text { Alkenes } \\
\text { Aromatic solvents } \\
\text { Chlorinated solvents } \\
\text { Cyclic hydrocarbons } \\
\text { Esters } \\
\text { Ethers } \\
\text { Glycols } \\
\text { Halogenated aromatics } \\
\text { Ketones } \\
\text { Refined petroleum } \\
\text { Refined petroleum } \\
\text { solvents }\end{array}$ \\
\hline
\end{tabular}


categories were office workers, sales, production of machinery, management, food and drink workers, computer programming, transportation, teachers, health care workers, and transportation and maintenance. The next column shows for each occupational category, the relative frequency of assigned ETS exposure. The next four columns show the two most frequently assigned occupational exposure agent categories and the percentage of jobs assigned with the exposure category.

Table 2 shows that the occupational categories with the highest percentage of jobs assigned to have exposure to irritant gases/vapors were welders, building maintenance, vehicle and equipment cleaning, production-machine operators, production-assembly, healthcare and productiontechnical workers. The lowest exposure frequencies for irritant gases/vapors were in the office workers and sales categories.

Diesel exposure was assigned mainly in transportation, material moving workers, mining, and logging. In the studied subjects, organic dust was most commonly assigned in wood production, logging, agriculture, and textile production. Organic solvents were commonly assigned in

Table 2. A List of Job Categories Coded for the Participants in the Case-Control study [11] and the Frequency Assigned

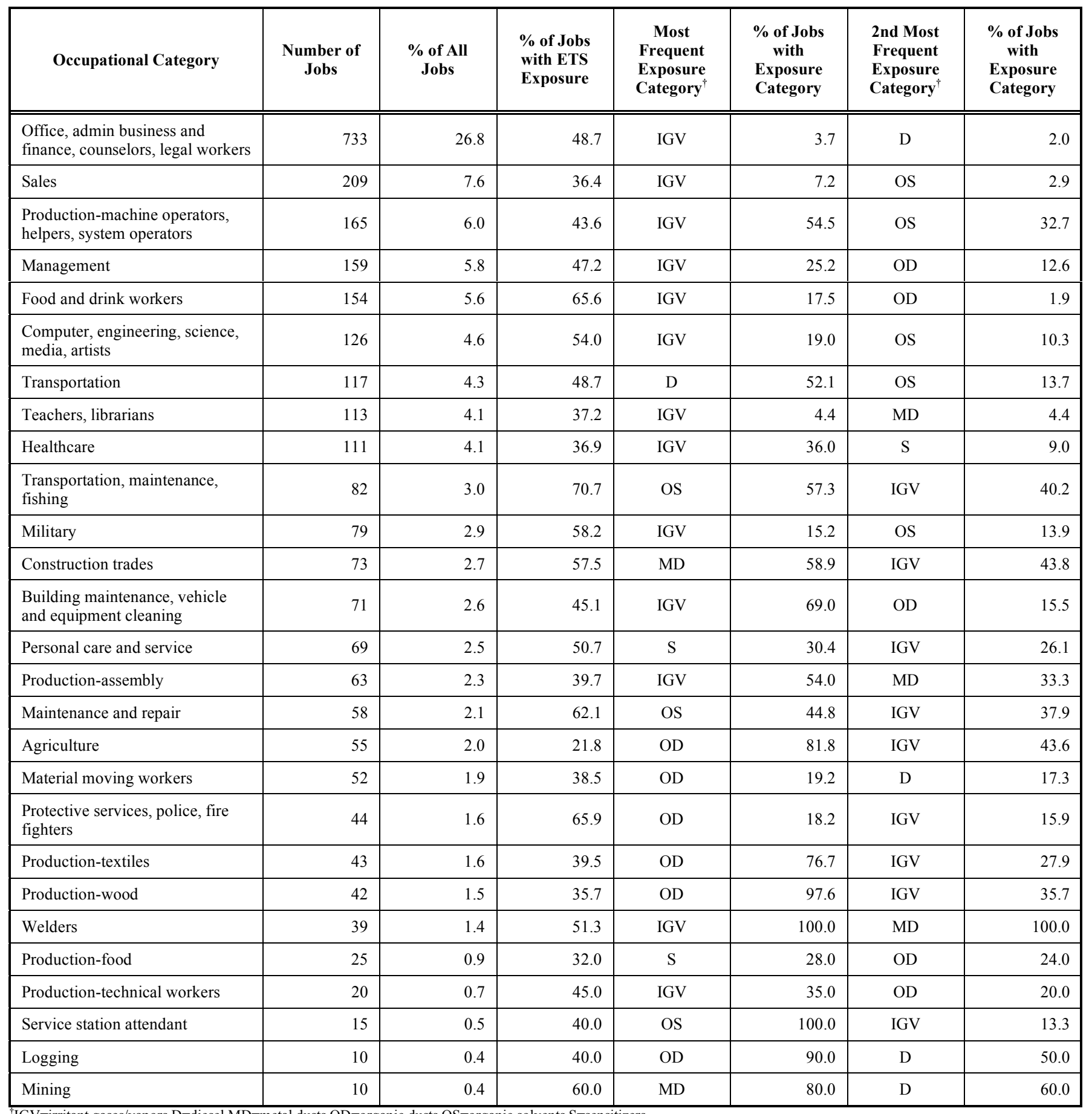

$\mathrm{IGV}=$ irritant gases/vapors $\mathrm{D}=$ diesel $\mathrm{MD}=$ =metal dusts $\mathrm{OD}=$ organic dusts $\mathrm{OS}=$ organic solvents $\mathrm{S}=$ sensitizers. 
Table 3. A List of the Top 10 Industry Categories Coded for the Participants in the Case-Control Study

\begin{tabular}{|c|c|c|}
\hline Industry Category & $\begin{array}{c}\text { Number of } \\
\text { Jobs }\end{array}$ & $\begin{array}{c}\text { \% of All } \\
\text { Jobs }\end{array}$ \\
\hline Information (newspaper, publishing, software publishing, data processing, radio, television broadcasting, wired telephones) & 328 & 12.0 \\
\hline Other services (automotive repair, car wash, dry cleaning, machinery and equipment repair, personal care services, funeral homes) & 303 & 11.1 \\
\hline Retail & 297 & 10.9 \\
\hline Health care & 225 & 8.2 \\
\hline Military & 202 & 7.4 \\
\hline Education & 182 & 6.6 \\
\hline Transportation & 153 & 5.6 \\
\hline Metal production & 149 & 5.4 \\
\hline Accommodation and food services (hotels, restaurants, bars) & 132 & 4.8 \\
\hline Construction & 97 & 3.5 \\
\hline
\end{tabular}

service station attendants, transportation maintenance, maintenance and repair. Sensitizers were frequently coded for personal care and services (includes beauticians) and food production. Table $\mathbf{3}$ includes the top ten most frequent industries among cases and controls.

The agreements in this study ranged from moderate to high agreement. The highest agreement was for environmental tobacco smoke at 0.88 (high agreement). Of the other occupational hazards, the highest agreement was for metal dusts at 0.66 (substantial agreement), and the lowest level of agreement was for the sensitizers category at 0.42 (moderate agreement). The Kappa coefficient for irritant gases/vapors was 0.49 and for diesel was 0.58 (both moderate agreement) [19]. In this study, the lowest agreement was a moderate agreement.

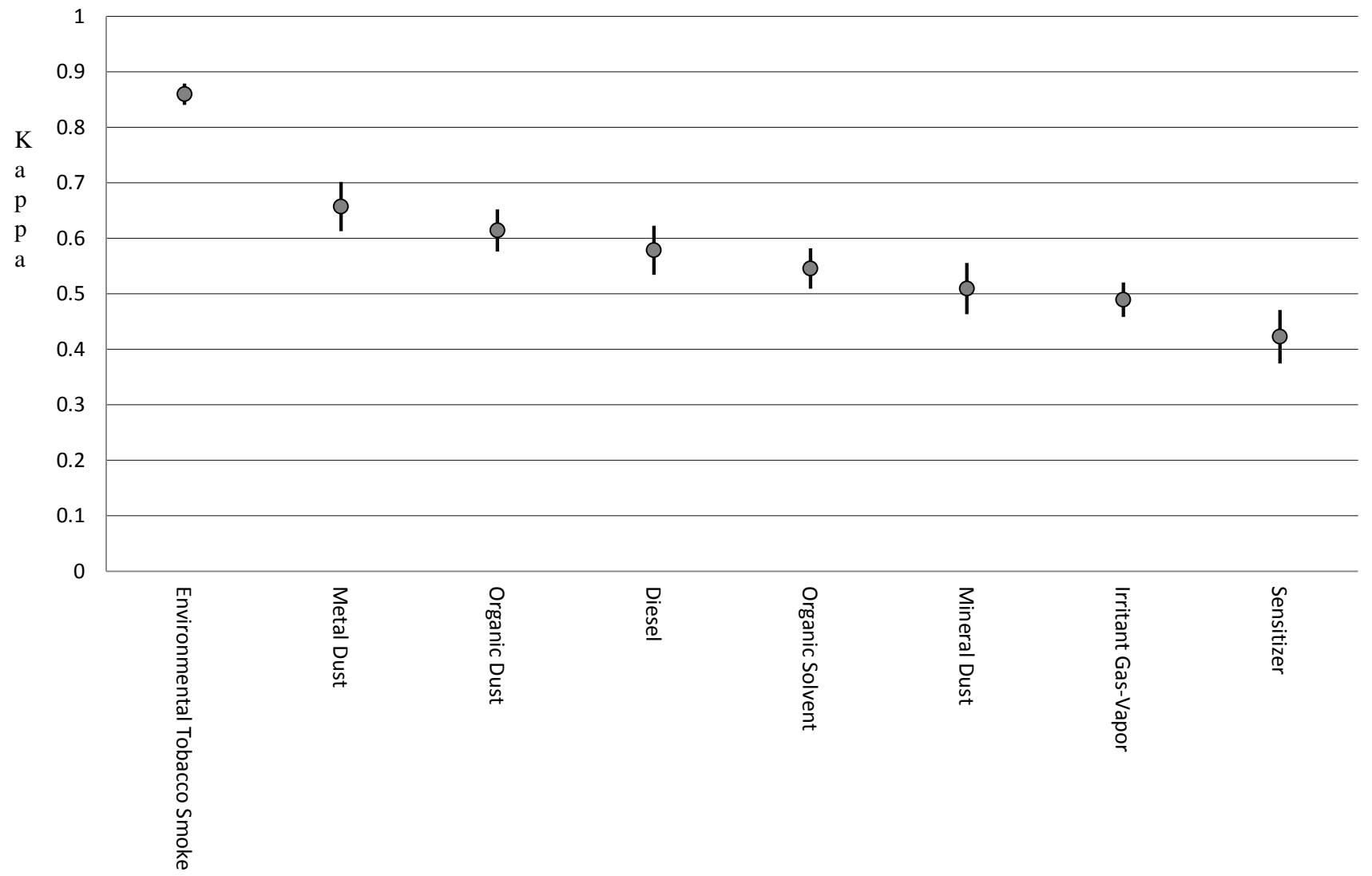

Fig (1). Agreement between NIOSH and KPCHR coders for specified exposure categories Kappa coefficient and level of agreement for exposure scores between 2 coders. 


\section{DISCUSSION}

The epidemiological evidence from population-based studies suggests that approximately $15 \%$ of the cases of COPD in society may be attributable to workplace exposures to dusts, noxious gases/vapors, and fumes [4-7]. Although, there is biological plausibility that persistent inhalation exposures over many years to high enough concentrations of dusts, fumes and irritant gases could cause lung damage eventually predisposing to COPD, appraisal of the contribution of occupational exposure to the COPD burden is complex. Because COPD has a complex multi-factorial etiology, with a strong effect of non-occupational risk factors such as tobacco smoking, population-based epidemiological studies based on well-assessed occupational exposure and tobacco smoking are needed to estimate the contribution of occupational exposures in the general population.

In population-based studies, the assessment of occupational exposure is usually made using questionnaire data on the longest held occupation often followed by applying a JEM to assign the potential occupational exposure, and/or response to questions on exposure to dust, fumes, and irritant gases [6]. In contrast, the current method of evaluation of lifetime occupational exposure based on life-time occupational history, response to questions on exposure to dust, fumes, and irritant gases, and independent assessment of potential exposure to eight occupational hazards by two industrial hygienists, described in this paper, has a potential for better occupational exposure ascertainment than a method based on longest held job and/or usage of JEM used often in previously published population-based studies of COPD [6].

However, to assess the method further, we evaluated the potential for misclassification of exposure. For this reason, the measure of agreement between two industrial hygienists was calculated to evaluate the consistency of coding of occupational exposures by the two scorers. Generally, the agreement between the two scorers on the individual exposure hazards based on the Kappa statistic was very good, especially on ETS, metal dust, organic dust, and diesel exhaust. Sensitizers had the least agreement (moderate). These results provide assurance of consistency of the assessment and potential usefulness of the method.

The potential usefulness of the method is also indicated by the results of the case-control study for which the exposure assessment was done. The results of the casecontrol study show a statistically significant association between COPD and exposure to irritant gases/vapors and diesel exhaust, and borderline significance for metal dust and mineral dust, after tobacco smoking and other potential confounding factors were adjusted for [11]. Occupational exposure to irritant gases/vapors can irritate the respiratory tract and have been shown in other studies to be associated with increased risk of COPD [7, 10]. Other studies have shown increased prevalence of COPD in welders [20] and also identified welding fumes [16] and solvent [21] exposures as risk factors for COPD.

Likewise, the association between COPD and diesel exhaust was also found in a case-control study of railroad workers by Hart et al. [22], where it was shown that work in jobs with exposure to diesel exhaust was associated with increased mortality from COPD. Other studies also reported an association between diesel exposure and increased risk of COPD mortality [23].

There are several limitations in our study. The exposure assessment relied on the industrial hygienist's expert opinion based on his/her knowledge of the industry and occupation, and partially on the information provided on the questionnaire by the study participants. Because of the time-span over which the exposures occurred, the questionnaire information was of great value. However, because no industrial hygiene sampling results or other documentation of exposures was available for exposure scoring, misclassification of exposures was likely to occur. Also, questionnaire responses on jobs and exposure could be affected by recall bias where cases could have more likely reported exposures than controls [24], especially since the occupational histories spanned many years. The study participants were drawn from the membership KPNW, a group model health maintenance organization. Most KPNW members receive coverage through their work. Industries with potentially high exposure to respiratory inhalants (e.g., agriculture, logging, mining, mineral products, and wood products) were less frequently represented. Other limitations may include: 1) the exposure assessment model used in this paper was not validated because it was based on questionnaire data and not actual exposure measurements, and 2) the experts that assigned exposures included only 2 industrial hygienists (although a third industrial hygienist reviewed $10 \%$ of NIOSH classifications). A disadvantage of this method is that it is time resource intensive in that each job over the workers lifetime is individually evaluated for eight exposure categories. However the interview length was reasonable, especially considering the amount of exposure information that was obtained. The chief advantage of this method is the detail about lifetime exposures, especially important given the longer time period for the development of COPD.

\section{CONCLUSION}

Generally there are inherent limitations in the method of occupational exposure ascertainment used in populationbased studies of COPD. However, lifetime occupational history and the high agreement between the exposure scores assigned by the two industrial hygienists, who independently scored each job reported by study participants, provide assurance of consistency of the assessment and its usefulness. In spite of its limitations, this methodology could prove useful for other studies. The strength of this study is that we obtained lifetime exposure history and evaluated organic dust, mineral dust, and metal dust in addition to irritant gasses/vapors and diesel potential exposure based on that history.

\section{ACKNOWLEDGEMENTS}

The authors would like to thank Greg Kullman and Aleks Stefaniak for their thorough and helpful technical review of this manuscript.

\section{FUNDING}

This study was supported by the AmericanAssociation of Medical Colleges (AAMC)/National Institute for Occupational Safety andHealth/Centers for Disease Control and PreventionCooperative Agreement No. MM-0247-03/03. 


\section{DISCLAIMER}

The findings and conclusions in this report are those of the authors and do not necessarily represent the views of the National Institute for Occupational Safety and Health.

\section{CONFLICT OF INTEREST}

The author(s) confirm that this article content has no conflicts of interest.

\section{ABBREVIATIONS}

COPD $=$ Chronic Obstructive Pulmonary Disease

ETS $=$ Environmental tobacco smoke

JEM = Job exposure matrix

KPNW $=$ Kaiser Permanente Northwest

\section{APPENDIX}

Excerpt from the Questionnaire for one job and an example of exposure scoring:

KPNW Study of Occupational COPD (OC-COPD): Clinical Interview

HRN:

Study ID

Date of interview: $\_-{ }^{\prime}-I^{\prime}-\ldots-\ldots$

Patient Gender:

Patient DOB:

Time interview began:

Time interview ended:

A. Employment

A_1. "Over your lifetime, have you been involved in paid employment for a total of 5 years or more? Include any homebased business."

Yes $\square 1$

No $\square 0$

If $A_{-} 1=$ "No," then member is ineligible. Thank them for their time and end the interview.

A_2. "Are you currently employed?"

Yes $\square 1$

If $A_{-} 2=$ "No," then ask $A_{-} 3$. Else, skip to J1_1 (CURRENT JOB).

No $\square 0$

A_3. "Are you retired?"

Yes $\square 1$

No $\square 0$

If A_3 = "Yes", then ask A_4. Else, skip to J2_4 (MOST RECENTLY COMPLETED JOB).

A_4. "When did you retire?"

Skip to J2_4 (MOST RECENTLY COMPLETED JOB).

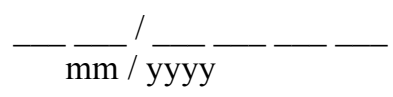

J1. Current Job

J1_1. "Who is your employer? (Probe, if necessary: "What is the name of the company or business?)" EMPLOYER 1:

J1_2. "What kind of business is this? (Probe, if necessary: "What is the product produced or service offered by your company or

business?)

J1_3. "What is your current position with this company?" (Probe, if necessary, for job title that describes occupation.)

POSITION A:

J1_4. "What are your tasks and activities on this job?"

J1_5-J1_6. "How long have you been working as a (position A name) for (employer 1 name)? If you've held more than one position with (employer 1 name), then I want you to tell me how long you've worked in this particular position for (employer 1 name)."

J1_7. "What year did you begin working as a (position A name) for (employer 1 name)"? 
If subject has difficulty recalling the year s/he started this job, ask J1_8. Else, skip to J1_9.

J1_8. "How old were you when you started working as a (position A name) for (employer 1 name)"?

J1_9. “On average, how many hours per week do you work on this job?" years old

hours/week

IF SUBJECT HELD JOB POSITION FOR < 6 MONTHS, SKIP TO QUESTIONS ABOUT THE NEXT JOB POSITION $\left(J 2 \_1\right)$.

J1_10. "Are you routinely exposed to dust, fumes, smoke, diesel exhaust, gases, or vapors while you are working on this job? By 'routinely' I mean once per week or more." (hone in on exposures specific to participant's position rather than what is generally in the work environment).

Yes__ No___ Unsure

If Yes, put a mark in the column to indicate which exposure, and askJ1_11 for each 'yes'.

If 'No', skip to J1 12

\begin{tabular}{|l|l|l|l|}
\hline & Yes & No & J1_11 What kind of ...? \\
\hline Dust & & & \\
\hline Fumes & & & \\
\hline Smoke & & & \\
\hline Diesel exhaust & & & \\
\hline Gases & & & \\
\hline Vapors & & & \\
\hline
\end{tabular}

J1_12. "Does your job routinely involve the use of chemicals? By chemicals, we mean things like solvents, cleaning agents, adhesives, paints and other coatings, pesticides, compressed gases, and cutting oils, as well as other chemicals." (hone in on exposures specific to participant's position rather than what is generally in the work environment.)

$$
\text { Yes__ No___ Unsure }
$$

If Yes, put a mark in the column to indicate which chemical, and ask J1_13 for each 'yes'.

If 'No', skip to J1_14

\begin{tabular}{|l|l|l|l|}
\hline & Yes & No & J1_13 What kind of ...? \\
\hline Solvents & & & \\
\hline Cleaning Agents & & & \\
\hline Adhesives or Glues & & & \\
\hline Paints or other coatings & & & \\
\hline Compressed Gases & & & \\
\hline Cutting Oils & & & \\
\hline Other chemicals & & & \\
\hline
\end{tabular}

An example of exposure scoring for a job: For each job that a participant held in their working lifetime, the interviewer completed the questionnaire (above). This information was available to the industrial hygienists conducting the scoring. The information from the literature was summarized (an example is listed in Table 1) from literature reviews. Using dust exposure for an example, if the job was a farm laborer, depending on responses to the interview, they likely would be assigned a 2 for exposure to organic dusts, a 2 for exposure to mineral dusts, and a lower score of 0 or 1 for metal dust, unless they also did welding. The overall score would be a 2 because of the exposure to dust, even if the score for each of the other categories was 0 or 1.

\section{REFERENCES}

[1] US Department of Health and Human Services. Health, United States, 2000, with adolescent health chartbook (DHHS Publication No. 2000-177). Hyattsville, MD: DHHS 2000.

[2] Becklake M. Occupational exposures: evidence for a causal association with chronic obstructive pulmonary disease. Am Rev Respir Dis 1989; 140: S85-S91.
[3] Oxman AD, Muir DCF, Shannon HS, Stock RR, Hnizdo E, Lange HJ. Occupational dust exposure and chronic obstructive pulmonary disease. Am Rev Respir Dis 1993; 148: 38-48.

[4] American Thoracic Society Documents. Occupational contribution to the burden of airway disease. Am J Respir Crit Care Med 2003; 167: 787-97.

[5] Mak GK, Gould MK, Kuschner WG. Occupational inhalant exposure and respiratory disorders among never-smokers referred to a hospital pulmonary function laboratory. Am J Med Sci 2001; 322: $121-6$. 
[6] Hnizdo E, Sullivan P, Bang KM, Wagner G. Association between chronic obstructive pulmonary disease and employment by industry and occupation in the US population: A Study of Data from the Third National Health and Nutrition Examination Survey. Am J Epidemiol 2002; 156: 798-46.

[7] Trupin L, Earnest G, San Pedro M, et al. The occupational burden of chronic obstructive pulmonary disease. Eur Respir J 2003; 22: 462-9.

[8] Bergdahl IA, Toren K, Eriksson K, et al. Increased mortality in COPD among construction workers exposed to inorganic dust. Eur Respir J 2004; 23: 402-6.

[9] Hnizdo E, Kennedy SM, Blanc PD, Toren K, Bernstein IL, ChanYeung M. Chronic airway disease due to occupational exposure. In: Bernstein IL, Chan-Yeung M, Malo JL, Bernstein DI, Eds. Asthma in the workplace. New York, NY: Taylor \& Francis Group LLC 2006; pp. 683-712.

[10] Harber P, Tashkin DP, Simmons M, Craford L, Hnizdo E, Connett J. Lung Health Study Group. Effect of occupational exposure on decline of lung function in early chronic obstructive pulmonary disease. Am J Respir Crit Care Med 2007; 176: 994-1000.

[11] Weinmann S, Vollmer WM, Breen V, et al. COPD and occupational exposures: a case-control study. J Occup Environ Med 2008; 50: 561-9.

[12] Boggia B, Farinaro E, Grieco L, Lucariello A, Carbone U. Burden of smoking and occupational exposure on etiology of chronic obstructive pulmonary disease in workers in Southern Italy. J Occup Environ Med 2008; 50: 366-70.

[13] Blanc PD, Iribarren C, Trupin L, et al. Occupational exposures and the risk of COPD: dusty trades revisited. Thorax 2009; 64: 6-12.

[14] Rodriguez E, Ferrer J, Marti S, Zock JP, Plana E, Morell F. Impact of occupational exposure on severity of COPD. Chest 2008; 134 : 1237-43.
[15]

Heederik D, Pouwels H, Kromhout H, Kromhout D. Chronic nonspecific lung disease and occupational exposures estimated by means of a job exposure matrix: the Zutphen Study. Int J Epidimiol 1989; 18: 382-9.

[16] Post WK, Henederik D, Kromhout H, et al. Occupational exposures estimated by a population specific job exposure matrix and 25 year incidence rate of chronic non-specific lung disease (CNSLD): the Zutphen Study. Eur Respir J 1994; 7: 1048-55.

[17] Occupational Safety and Health Administration. Industry Profile for an OSHA Standard [Online]. 2007 Mar 19, Available from: http: //www.osha.gov/pls/imis/industryprofile.html [cited 2012].

[18] Stellman JM, Ed. Encyclopedia of Occupational Safety and Health, $4^{\text {th }}$ ed. Geneva: International Labour Organization 1998.

[19] Landis RJ, Koch GG. The measurement of observer agreement for categorical data. Biometrics 1977; 33: 159-74.

[20] Bakke PS, Baste V, Hanoa R, et al. Prevalence of obstructive lung disease in a general population: relation to occupational title and exposure to some airborne agents. Thorax 1991; 46: 863-70.

[21] Lebowitz MD. Occupational exposures in relation to symptomatology and lung function in a community population. Environ Res 1977; 14: 59-67.

[22] Hart JE, Laden F, Schenker M, Garshick E. Chronic obstructive pulmonary disease mortality in diesel-exposed railroad workers. Environ Health Perspectives 2006; 114(7): 1013-7.

[23] Garshick E, Laden F, Hart JE, Rosner B, Smith TJ, Dockery DW. Lung cancer in railroad workers exposed to diesel exhaust. Environ Health Perspect 2004; 112(15): 1539-43.

[24] Szklo M, Nieto FJ. Epidemiology: beyond the basics. Boston: Jones and Bartlett 2004; pp. 136-83.

Received: February 7, 2012

(C) Work of the United States Government; Licensee Bentham Open.

This is an open access article licensed under the terms of the Creative Commons Attribution Non-Commercial License (http://creativecommons.org/licenses/by$\mathrm{nc} / 3.0 /$ ) which permits unrestricted, non-commercial use, distribution and reproduction in any medium, provided the work is properly cited. 